\title{
SECOND ORDER ARITHMETIC MEANS IN OPERATOR IDEALS
}

\author{
VICTOR KAFTAL AND GARY WEISS
}

Abstract. We settle in the negative the question arising from [3] on whether equality of the second order arithmetic means of two principal ideals implies equality of their first order arithmetic means (second order equality cancellation) and we provide fairly broad sufficient conditions on one of the principal ideals for this implication to always hold true. We present also sufficient conditions for second order inclusion cancellations. These conditions are formulated in terms of the growth properties of the ratio of regularity sequence associated to the sequence of s-number of a generator of the principal ideal. These results are then extended to general ideals.

Mathematics subject classification (2000): 47B10, 47L20, 46A45, 46B45, 47B47.

Key words and phrases: Operator ideals, principal ideals, s-numbers, arithmetic means, cancellation.

\section{REFERENCES}

[1] Connes, A., Non Commutative Geometry, San Diego Academic Press, 1994.

[2] Calkin, J. W., Two-sided ideals and congruences in the ring of bounded operators in Hilbert space, Ann. of Math. (2) 42 (1941), pp. 839-873.

[3] Dykema, K., Figiel, T., Weiss, G. AND WodZICKI, M., The commutator structure of operator ideals, Adv. Math., 185/1 pp. 1-79.

[4] Hardy, G. H., Littlewood, J. E. And Pólya, G., Inequalities, 2d ed. Cambridge University Press, 1952.

[5] GohberG, I. C. And KrĕN, M. G., Introduction to the Theory of Linear Nonselfadjoint Operators, American Mathematical Society (1969).

[6] Kaftal, V. And WeIss, G., Traces, ideals, and arithmetic means, Proc. Natl. Acad. Sci. USA 99 (11) (2002), pp. 7356-7360.

77] KaftaL, V. AND WeISS, G., Traces on operator ideals and arithmetic means, preprint.

[8] KAFTAL, V. AND WeISs, G., Soft ideals and arithmetic mean ideals, IEOT, to appear.

[9] KafTAL, V. AND WeISS, G., B $(H)$ lattices, density, and arithmetic mean ideals, preprint.

[10] KAFTAL, V. AND WEISS, G., Majorization for infinite sequences and operator ideals, in preparation.

11] Kalton, N. J., Trace-class operators and commutators, J. Funct. Anal. 86 (1989), pp. 41-74.

[12] Marshall, A. W. And Olkin, I., Inequalities: Theory of Majorization and its Applications, Academic Press Inc. [Harcourt Brace Jovanovich Publishers], Mathematics in Science and Engineering 143 (1979).

[13] WeIss, G., Commutators and Operators Ideals, dissertation (1975), University of Michigan Microfilm.

[14] WeIss, G., Commutators of Hilbert-Schmidt operators, II, IEOT 3 (4) (1980), pp. 574-600.

[15] WeISs, G., Commutators of Hilbert-Schmidt operators, I, IEOT 9 (6) (1986), pp. 877-892.

[16] Varga, J., Traces on irregular ideals, Proc. Amer. Math. Soc. 1073 (1989), pp. 715-723. 